\title{
Beyond Minimisation of Personal Healthcare Financing Risks: An Ethnographic Study of Motivations for Joining Ghana's Health Insurance Scheme in Daakye District
}

\author{
Kwadwo Adusei-Asante ${ }^{1}$ \\ School of Arts and Humanities, Edith Cowan University \\ K.adusei@ecu.edu.au
}

\begin{abstract}
This article discusses the manner in which local contexts influence people to join health insurance schemes. The text is based on an ethnographic study that explored the modes of use of Ghana's National Health Insurance Scheme (NHIS) in the Daakye District, Ghana. The content is drawn from the author's Master of Anthropology thesis and the themes that emerged from participant observation and interviews with thirty respondents. Five reasons why people joined the NHIS in the research locality are presented. The findings show that 1 ) the prevailing sociocultural realities of Daakye District - where individuals saw themselves as being part of families, with socio-economic obligations-influenced how the local people received and used the NHIS; 2) people bought health insurance policies to minimise the healthcare financial risks for themselves and their families and other strategic reasons and 3) the conceptual framing of Ghana's NHIS policy was biased towards the individual rather than families. The study recommends a review of the individual focus of the NHIS to improve its cost effectiveness and operational efficiencies.
\end{abstract}

\section{Introduction}

Health insurance is considered the best way to promote community involvement in healthcare financing, while maintaining access to virtually free healthcare at times of illness, especially for the poor (Arhin-Tenkorang,

\footnotetext{
${ }^{1}$ Thanks to Professor Birgit Meyer who supervised my thesis; the Department of Social and Cultural Anthropology of the Vrije University of Amsterdam, Holland, which provided the scholarship for this research; and Mrs Tamara Findlay for proofreading this text.
} 
1994; Mariam, 2003). In most developing countries, where poverty impedes access to quality healthcare, health insurance is considered key to removing financial circumstances as a barrier to healthcare access and utilisation. In the case of Ghana, Asenso-Okyere (1995, p. 87) has argued that:

In the search for a suitable option for financing healthcare ... health insurance has been widely discussed. It has often been anticipated that health insurance will provide the funds for improving healthcare delivery and increase access to healthcare, especially for the poor and vulnerable.

Political expediency and various academic research recommendations spurred the Government of Ghana to implement a 'pro-poor' National Health Insurance Scheme (NHIS) in 2004 (Adusei-Asante \& Doh, 2016; Arhinful, 2003; Blanchet, Fink, \& Osei-Akoto, 2012). The policy replaced the existing system in which 'out-of-pocket' fees were required at the point of service use. The government's objective in setting up the NHIS was to assure equitable and universal access for all residents of Ghana to an acceptable quality package of essential healthcare (Agyepong \& Adjei, 2008; Ministry of Health, 2004).

Previous studies on the reasons people buy health insurance policies appear to have focused on the somewhat simplistic view of the unpredictability of medical spending and the degree of risk aversion of the individual at the time of receiving healthcare (see Agyepong \& Adjei, 2008; Asenso-Okyere, Osei-Akoto, Anum, \& Appiah, 1997; Cutler \& Zeckhauser, 2000; Arhinful, 2003; Dixon, Tenkorang, \& Luginaah, 2011; Blanchet, Fink, \& Osei-Akoto, 2012; Lagomarsino, Garabrant, Adyas, Muga, \& Otoo, 2012). These studies did not consider the health insurance buyers' motivations to minimise their healthcare financing risks from a cultural anthropological perspective.

This article attempts to fill a gap, by unpacking the manner in which sociocultural nuances drove people's decisions to buy, keep or opt out of Ghana's NHIS. The research conducted in 2009 in the Daakye District of Ghana (for the purposes of protecting the identity of the research subjects, the name of the locality where data was collected, its hospital and other local not-forprofit organisations that provided relevant information have been deidentified with pseudonyms), found that the country's NHIS tended to consider its clients on an 'individual' basis, ignoring the local reality that these individuals formed part of families involving members with mutual socio-economic obligations. Within this 'collective context', people who 
joined the NHIS contradicted the 'individual bias' of the NHIS; thus, clients exploited the policy in ways that affected its operational efficiency and cost effectiveness.

\section{Background to Ghana's National Health Insurance Scheme}

Ghanaians enjoyed free medical care following Ghana's independence from British colonial rule in 1957. From the 1980s, individuals' healthcare requirements had to be paid for by patients, and many Ghanaians were unable to afford these costs (Senah, 1997; Agyepong \& Adjei, 2008; Arhinful, 2003). The World Bank and International Monetary Fund Structural Adjustment Program became a major feature of Ghana's economic policy in the 1980s, leading to health sector reforms that ushered in the introduction of user fees ('out-of-pocket' payments) in public health facilities, as well as the 'full cost recovery' of prescription drugs (AsensoOkyere et al., 1997; Agyepong \& Adjei, 2008). The program's objective was to raise revenue and deter 'frivolous' use of scarce health resources in Ghana. Even though the measure was believed to have led to some improvements in the public health sector, potential patients were often precluded from healthcare because of their inability to pay for services. There was also the challenge of identifying genuine paupers and indigents, who were exempt from the 'user pays' system (Arhinful, 2003).

An initiative adopted by African health ministers in Bamako in 1987 was expected to improve the availability of essential drugs and health policies of sub-Saharan African countries. The initiative stated that the United Nations Children's Emergency Fund (UNICEF) and World Health Organization (WHO) should purchase drugs and sell them to communities at affordable prices. A community could then use the savings to upgrade its basic healthcare system (Kanji, 1989; McPake, Hanson \& Mills, 1993). However, Ghana did not make progress with the initiative and abandoned it in 1990 (Arhinful, 2003). The government returned to the 'cost recovery' system for drugs in 1992, known as 'cash and carry,' which meant that health institutions had to pay for the drugs they collected from medical stores. The rationale behind this policy decision was to make health institutions more efficient in the management of drugs at the sub-district level (AsensoOkyere, 1995; Arhinful, 2003; Agyepong \& Adjei, 2008). Some successes were recorded, but concerns were raised about affordability for low-income patients, paupers and indigents, and for emergency treatments (AsensoOkyere 1995; Arhinful, 2003). Following this development, the National Democratic Congress government under President Jerry John Rawlings 
(1992-2000) piloted health insurance in four districts of the Eastern Region of Ghana in 1997. However, as Arhinful (2003) argued:

The project stalled in 1998, although this was not officially admitted. Rather, the state maintained a deceptive public image that the schemes were progressing well, and results were being studied, when in fact there was no intention of actual implementation taking place (p. 62).

In 2003, John Kofi Agyekum Kufuor's government (2001-2008) passed the National Health Insurance Act, 2003 (Act 650). The Act sought to replace the 'cash and carry' system and improve access among Ghanaiansespecially the poor and vulnerable - to basic quality healthcare services. The Act also made it mandatory for all Ghanaians to join the various district mutual health insurance schemes (DMHIS) (Boakye, 2008; Agyepong \& Adjei, 2008). Act 852 replaced Act 650 in 2012, classifying all DMHIS under the NHIS (Blanchet et al., 2012). Ostensibly, under the NHIS, 'the rich' help subsidise 'the poor', 'the healthy' subsidise 'the sick', and 'the economically active' pay for children, the aged and indigents. As OseiAkoto (2004) noted:

It is a social policy; a kind of social re-engineering that caters for the most vulnerable in the society through the principle of equity, solidarity, risk sharing, crosssubsidization, re-insurance, subscriber / community ownership, value for money, good governance and transparency in the health care delivery (p. 6).

Ghana's NHIS operates as an indemnity policy. In this model, the insurance pays a fixed amount of money for particular illnesses when individuals become sick. Arguably, no resources are wasted because there is 'no more and no less' assistance made available than a patient needs to 'consume'. For each disease, the policy reimburses an amount equal to the cost of treatment (Cutler \& Zeckhauser, 2000). Formal sector workers, Social Security and National Insurance Trust (SSNIT) contributors, indigents, and people below the age of 18 (the legislative instrument states that before a minor under 18 can be registered, at least one parent must join the NHIS) or over 70 (called the exempt group) do not pay premiums; although in some mutual health insurance schemes they pay varying sums as 'administrative costs'. The benefits package includes primary care and 
hospital care (outpatient and inpatient care), oral health services, eye care services, maternity care and all emergencies. The NHIS covers 95 per cent of all diseases in Ghana, including the top 10 health concerns that make up 80 per cent of the disease burden in the country. There is also no ceiling on how many times clients can visit health facilities (National Health Insurance Authority [NHIA], 2016); however, a gatekeeper system is in operation that ensures that patients access healthcare offered mainly through primary health centres (district hospitals, polyclinic health centres, clinics, maternity homes, Community Health and Planning Services, and pharmacies). At the time of data collection in 2009, Ghanaians who had joined the NHIS could not practically use it everywhere in the country, although the policy allowed this in principle.

Healthcare providers operate under contract with predetermined tariff structures (based on the Ghana Diagnostic Related Groupings). They must file claims in a timely manner and adhere to specific guidelines to obtain reimbursement for contracted services. Payments are made within the limits of a defined benefits package, and patients bear any costs that go beyond the stipulated limits (NHIA, 2016). In 2009, new clients joining the scheme had to wait for three months before their membership could be activated. Within those three months, although they were registered, new clients could not benefit from the scheme and were still required to make 'out-of-pocket' payments if they visited a health facility. Existing clients had to renew their policies annually.

The NHIA oversees the various mutual health insurance schemes, coordinates related activities and manages the National Health Insurance fund. The National Health Insurance Regulations, 2004 (NHIR) guide the continued operation of Ghana's NHIS. Under the NHIR, healthcare providers are obliged to apply for and pass accreditation appraisals to qualify for service provision under the scheme. Health facilities have specific requirements to fulfil, which include having a functional quality assurance program that ensures professionals working in the facilities are legally qualified. The NHIA is also mandated to institute a performance monitoring system for accredited healthcare facilities. Monitoring activities include: periodic inspections of health facilities and other offices; collection of data from services rendered; periodic data analysis to check the quality, cost and effectiveness of services and adherence to accepted and known standards of practice; peer review; and mandatory reporting approved by the NHIA (Yeboah, 2008; Legislative Instrument (L.I.) 1809, 2004; NHIA, 2016). 


\section{Daakye District}

The Daakye District ('the District') is located in the Central Region of Ghana. In 2009, at the time of fieldwork, over 150,000 people resided in the district, with 95 per cent living in very rural settings. The district had more than 700 communities (towns, villages and hamlets), with one-third on islands accessible only by boat. Only 10 per cent of the entire road network in the district was coal tarred, while only 32 communities had electricity. The main languages spoken were Akan and Ewe. Local ethnic groups comprised the Tali (48\%), Buru (27.5\%), Northerners (22.3\%) and other groups (2.2\%). The District had 151 primary schools, 44 junior secondary schools, two secondary schools, one technical/commercial school and two vocational institutes. Daakyekrom, the district's capital, had a population of almost 8,000 people at the time. The diverse cultural backgrounds of residents were reflected in the variety of local churches, including Orthodox, Pentecostal and Neo-Pentecostal faiths. Muslims comprised almost 30 per cent of the entire population of Daakyekrom (Daakyekrom Development Organisation Annual Reports [DDOAR], 2006 to 2008).

Daakye District remains one of the most undeveloped, deprived and poverty-stricken districts in Ghana (DDOAR, 2006 to 2008). Vast water resources for fishing and fertile land for farming and livestock mean that food production (mainly yams and maize), fishing, charcoal burning and cattle rearing are major economic activities. Trading in fish, livestock and foodstuffs has become very important for economic productivity. Economic activities tend to be concentrated around Daakyekrom, and the financial situation of most communities is one of economic deprivation. Indeed, barter trade still exists in the Daakye District (DDOAR, 2006 to 2008).

In 2009, the entire District had only one referral hospital (the Daakyekrom Mission Hospital [DMH]), three clinics and thirteen Community Health Promotion Services (CHPS). On most of the islands, there were neither clinics nor CHPS, with people forced to cross the Odo River (sometimes taking eight hours) to access the nearest health facility. Daakyekrom and a nearby community, Adeemmra, were the only communities in the district furnished with a piped water system. Sources of water supply for the other communities included lakes, rivers, boreholes and rain harvest. Prevalent health issues included malaria, hernias, respiratory tract infections and typhoid fever. Due to the paucity of health facilities in the area, most people relied on pharmaceutical outlets (drugstores) and traditional medicines (DDOAR, 2006 to 2008).

As poverty has always been a barrier to healthcare access in the Daakye District, a Community-Based Health Insurance Scheme (CBHIS) had been 
in operation before the NHIS was introduced. The district's Director of Health established this initiative in 2000, supported by international donors. Operating at the $\mathrm{DMH}$, the CBHIS sought to address preventable deaths in the district through helping the local people access healthcare at a subsidised cost. Even so, many people could not afford even subsidised healthcare at the $\mathrm{DMH}$, resulting in some absconding from the facility when 'half-fit,' to avoid the payment of medical costs. As a result, the CBHIS incurred significant debt and was short-lived. The government introduced the NHIS in the district in 2004 to replace the CBHIS (DMH Reports, 2006 to 2008; personal communication with Daakyekrom District Director of Health Services). One would have expected that, being 'poor', most of the local people in the Daakye District would join the NHIS and fully use it. However, the data showed evidence to the contrary.

\section{Methods}

The findings presented in this paper have been extracted from the author's Master of Anthropology thesis. The fieldwork for the thesis took place over a three-month period in 2009. I worked mainly in Daakyekrom, its environs and on the Reda Islands. Being a male researcher working in a patriarchal environment, conscious efforts were made to mitigate power asymmetries between the female research participants and myself. For example, I wore only casual clothes in the field and took part in local activities such as church activities and communal labour. Participant observation and interviews were the main research instruments used.

I closely observed and participated in the activities of the $\mathrm{DMH}$, drugstores, traditional medicine, faith healing and other relevant activities. At the hospital, I observed the general conditions, outpatient day activities and the procedures that patients experienced before and after attending the consulting room. I sat with medics to participate in the diagnostic process, which took place at different times on market and ordinary days. Tuesdays were market days in the locality, bringing together many traders from inside and outside the district. The number of outpatient visits to the $\mathrm{DMH}$ on market days was high and allowed me to observe many events and interact with many patients. My presence at three drugstores as an observer and a participant brought me into contact with people in Daakye District from various social strata and geographical locations, particularly on market days. I visited and observed the activities of traditional medical practitioners. I attended the services of two faith healers and observed their healing procedures, and teachings on causes of illness and listened to prayers 
intended to heal the sick. I also witnessed the activities of the main mosque and interacted with the Imam and some Muslims in Daakyekrom.

Apart from the Reda Islands, where a translator was used, most of the interviews were conducted in the Akan language, in which I am fluent. A total of 30 interviews were conducted with people (half women, half men) between the ages of 22 and 80 years, representing different social strata. Formal interviews were conducted with medics, drugstore operators, traditional medical practitioners and faith healers. Interview questions focused on the health situation in the Daakye District, both before and after the introduction of Ghana's NHIS, how the policy had influenced their work, and what they believed the future may hold for them. Some individuals in Daakyekrom who had insights about the Daakye District were also engaged in formal interviews. These included the directors of various non-government organisations (NGOs) and the District Director of the Ghana Health Services.

The remaining interviews were informal. I engaged with individuals on the Reda Islands as well as in the streets, homes and workplaces of Daakyekrom. I interacted with and interviewed the users of drugstores, traditional medicines and faith healers at their respective centres. In the process, I encountered former and current users of the NHIS. They were asked 'why' they had joined the scheme, if they had received any benefits since enrolling and, where applicable, why they had opted out of the scheme after receiving treatment.

Data analysis began in the field with categorisation of the data sets and transcription of all interviews. The data was manually coded after being read closely in three rounds to establish themes, as well as the extent of convergence between the data sets (Liamputtong, 2013). While five major themes were identified in the final Master of Anthropology thesis (AduseiAsante, 2009), the 'motivations for joining the NHIS' is the particular theme and focus of this article.

\section{Why people joined the National Health Insurance Scheme in Daakye District}

The local cultural context and patterns of family obligations in Daakyekrom influenced how people related to the NHIS. As in most Ghanaian rural localities, Daakye District was androcentric, meaning it had a cultural belief system requiring 'men to look after women.' Most people in Daakyekrom identified as either Christian or Muslim and, in both faiths, women/wives were required to 'submit' to their men/husbands, who were supposed to protect and provide for them. Faith aside, men were expected to 
take care of their wives, children, parents and other relatives, especially younger family members in school and aged individuals (Adusei-Asante, Hancock, \& Oliveira, 2015). In some cases, husbands were also expected to provide support for their in-laws. While in the field, I witnessed a traditional marriage ceremony in Daakyekrom, which confirmed these patterns of family obligation. Before the bride was 'handed to the man', the traditional leader moderating the ceremony declared that:

If you marry a woman, you marry her whole family. If she and her family are in debt, you are in debt. If she gets anything good and valuable [children], they belong to her family. If you beat her, we will come for our daughter and do not dare to ask for your dowry back; because it will be her compensation.

Most women in the Daakye District worked in the informal sector as traders, farmers and seamstresses. Even though married women depended on their husbands for support, they (along with single women) were also expected to look after their parents and sometimes other relatives. Thus, husbands were expected to pay NHIS membership not only for themselves but for their wives and children, parents and their wives' parents (if poor and aged, but generally only in extreme cases). Single males and husbands in the district had been socialised to accept these responsibilities and often remarked in Akan during interviews with the researcher that: 'Se yewo wo barima a, $3 y 3$ asem', meaning 'if you are born a male, you have lots of responsibilities'. Many Daakyekrom men joined the NHIS to meet the healthcare needs of their dependents and minimise the responsibilities culturally associated with manhood in the local district.

This research reveals that the main reasons for joining the NHIS in Daakyekrom are related to family. The following section discusses these reasons. The data shows over 70 per cent of respondents joined the NHIS to minimise risks related to financing healthcare for themselves should they fall ill and need money to pay for medical services. For these respondents, the NHIS provided a form of 'security'. This was not surprising as it is the main goal of health insurance service providers and customers.

However, several other dimensions of the use of Ghana's NHIS were also revealed, leading the researcher to categorise several subgroups of NHIS users, specifically those who: 1) aimed to minimise healthcare financial risks for themselves and/or others; 2) enrolled only because of their dependents' (potential) health needs; 3 ) joined to have a specific illness 
treated, subsequently opting out of future NHIS renewal payments; 4) were 'sponsored' NHIS holders; or 5) held 'double' NHIS policies. These are discussed in turn below.

\section{Minimising the healthcare financial risk for oneself and others}

To reiterate, the people of Daakyekrom lived within a social context that places specific family obligations and responsibilities on males, who are expected to take care of themselves, their families and any in-laws. Therefore, for most men (and especially husbands) in Daakyekrom, the NHIS was viewed as a financial necessity for themselves and their dependents. For example, one interviewee, Jonathan, was a 42-year-old farmer, businessman and driver. He frequently travelled to the city to sell charcoal and yams in trucks. He accessed the NHIS personally, while also paying enrolment costs for his two children, his wife and her parents. His reasoning was as follows:

I have two children and [am] married to a lady whose parents are poor. For us, the NHIS is a saviour because my wife's parents look up to her, and she looks up to me, even though she also works. So we joined the NHIS not just because I travel a lot, but because I may not have money readily available to pay the medical bills of my kids, my wife, and her parents when they fall sick unexpectedly.

He further explained that his children and in-laws had benefitted from the scheme immensely. When asked if he had renewed their premiums in the year, he said:

Yes, particularly for myself. You see this thing? [He points to his truck] It's a machine and can be involved in an accident anytime and anywhere. I understand that if you have the NHIS, you can go to any hospital in Ghana and be treated. So being a man on the road, I need the NHIS so that in case of an accident, I can be looked after at any health facility.

Even though Jonathan appeared unaware of the administrative burden of using the NHIS outside the Daakye District, he had joined the NHIS to minimise risk for himself, his immediate family, and his in-laws. It is worth noting that at the time of data collection, the practice of seeking healthcare 
under the NHIS outside one's district was a complicated process. Although it was possible in principle, it required administrative processes that some Ghanaians found excessively bureaucratic. These administrative processes have been improved, allowing people to access healthcare with the NHIS in all parts of the country with relative ease (see Fenny, Asante, Arhinful, Kusi, Parmar, \& Williams, 2016).

\section{Minimising healthcare financial risks exclusively for dependents}

The legislative instruments underpinning the NHIS indicated that minors below 18 years of age were exempt from paying premiums, even though in the Daakye District they were required to pay GH\$4 (approx. AU\$2) in administrative costs. Until the beginning of 2008, pregnant women in Ghana could only receive antenatal and postnatal care if they were NHIS members or made out-of-pocket payments. Before this, many women who delivered babies and had no money to pay were kept at the hospital-with their newly born babies-sometimes for months. This resulted in debt accumulation until a relative or a philanthropic organisation paid to release them following a public appeal.

In 2008, the Government of Ghana secured a £42 million (approx. A\$71 million) loan from the British Government, which was used to establish a free, national maternal care system. Under this arrangement, regardless of whether they were members of the NHIS, mothers were not required to pay medical fees after the delivery of their child. However, new mothers were expected to either enrol in the NHIS or make 'out-of-pocket' payments to seek postnatal care for themselves and their babies. This initiative led to a rise in the number of deliveries at public medical centres around the country (Kajsa, 2008; Ghana News Agency, 2009; Dogbevi, 2011). The 2008 DMH annual report shows that the free maternity policy influenced the number of deliveries at the facility. Specifically, the hospital recorded 496 births in 2006, 540 in 2007 and 751 in 2008.

Some women interviewed in Daakyekrom who had just delivered their babies claimed to be healthy and stated that they would rely on herbal medicines for their postnatal healthcare needs. However, they were still concerned about their newborn babies:

Do I look sick? If the delivery were not free, I would not even go to the hospital to deliver. I have delivered all my children at home with the help of a traditional birth attendant. My husband registered me in the NHIS because of our baby. 
This respondent joined the NHIS in 2008, but only after her husband enrolled. She explained that she did not have plans to renew her NHIS membership. Even so, because of their baby, it was likely that her husband would renew the NHIS for another year at least and then opt out until another pregnancy. The DMH annual reports from 2004 to 2007 revealed an interesting picture in this regard. In 2004, 11,244 children and minors were registered in the scheme along with 6,581 adults. In 2005/6, the numbers of children and adults were 19,370 and 10,085 respectively. By 2006/7, it had grown to 24,306 children and 12,973 adults registered. This matches the pattern observed in the current study, that most parents (and adults in general) deemed it important to register their children, viewing it as both their responsibility and a way to minimise their health financing risk.

\section{Exclusively for medical condition(s)}

Those who joined the NHIS exclusively for medical conditions fell into two groups: people who had been diagnosed with covered diseases and could not afford the 'out-of-pocket' hospital payment; and those who, by the nature of their jobs, expected to contract a disease in future, but feared they might not be able to pay 'out-of-pocket'. Among men in the Daakye District, developing a hernia was one such (predicted) disorder. A medic at the Daakyekrom Hospital explained to me that hernias were the main surgical conditions among adult male patients in the Daakye District, due to it being a farming community requiring primarily manual work. Some respondents had joined the NHIS simply because they had been diagnosed with a hernia and required treatment. At the time, it could cost patients almost GH200\$ (approx. A \$70) to remove a hernia, but they were treated free of charge under the NHIS. The DMH annual reports from 2006 to 2008 showed a steady yearly increase of 30 per cent in surgical cases at the facility, with hernias being one of the top four causes of admission after malaria, child delivery and anaemia (DMH Annual Report, 2006 to 2008).

Abu was an unmarried, 35-year-old Muslim male, who lived in Bease. I ran into Abu while he was performing one of his many manual labour jobs and, after obtaining his consent, I interviewed him. He had lived in Daakyekrom and smashed rocks by hand for almost 10 years to earn a living. Abu explained that he only joined the NHIS in 2006 because he needed to get rid of a hernia he suffered in 2005. Abu had the hernia removed under the NHIS in 2006 free of charge. Abu explained that he would have paid GH200\$ out-of-pocket if he had not joined the NHIS. Tellingly, Abu did not renew his NHIS membership in 2007, and when asked why he did not his 
response was "I have got what I wanted". Abu's remark suggests that he joined the NHIS only to get the hernia removed and opted out when he had no medical condition to treat under the NHIS.

Apart from respondents like Abu, who had already benefitted from the NHIS, there were others who had joined pre-emptively because of their jobs. These were mostly manual labourers who had not been diagnosed with a hernia or any serious condition as yet, but felt that the nature of their jobs made a future diagnosis a likelihood. For these men especially, the NHIS was the cheapest means of treating one's hernia or other surgical problems, be it actual or anticipated.

A similar, but nuanced, trend was reported among some women in the district. In fact, the annual reports of the Daakyekrom Insurance Scheme (2006-2008) indicated that women joined the policy and sought healthcare (in general) at a greater rate than men. During a three-day participant observation in the consulting rooms of the $\mathrm{DMH}$, I recorded 69 women among the 100 adult patients who came to see the medic. Two categories of women who used the NHIS were found. The first category consisted of women who (a senior nurse at the DMH told me during an interview) had been operated on for female-specific conditions (such as fibroids) under the NHIS and were never seen again at the hospital. The senior nurse explained that while fibroids were common with women in the district, most of them could not afford the treatment out-of-pocket. As a result, the NHIS provided women with the opportunity to treat the condition, after which they would opt out of the policy until they needed treatment for a different health condition.

Aside from the case of the 'opt in and opt out' category above, I encountered people in the field who perceived the NHIS as a necessity for women even if they did not visit hospital very often. In the Reda Islands, I interviewed a 57-year-old man who had previously joined the scheme but had since opted out. He had five children and had not renewed his personal NHIS membership at the time of data collection, but had re-enrolled his wife and children:

Well look at my age; I'm almost gone [dead] so why worry ... it is not that I cannot afford ... for the past 20 years I have never been to the hospital, it is the woman and children who matter.

He went further to explain why he felt that caring for women was important: 
We men are strong and can deal with a lot of things in our bodies even if we are old. But women cannot. They are complex in everything and need doctors and clinics. From the day they get pregnant to the time they deliver, they need medical assistance. I want to have more children so my wife needs the NHIS so that she can attend antenatal and postnatal services free of charge.

On the physiology of women and the socio-cultural perception that they need greater medical attention, a lady in the Reda Islands revealed the following:

I joined the scheme in 2007 when I became pregnant. My pregnancy was complicated, and I needed medical help. It was not easy travelling [to the] Daakyekrom clinic, but it was worth it. Traditional herbs did not help much after trying it over and over. It was the hospital that saved me, and if we did not have the NHIS, it would have been very expensive.

This respondent also implied that if her husband no longer renewed her premium, she would register (herself) because she needed to go the hospital for regular abdominal and medical reviews. The general feeling among women was that the NHIS was important. Thus, they impressed upon their husbands the necessity of enrolling and renewing payment of their NHIS costs for themselves (family members).

\section{Sponsored National Health Insurance Scheme members}

This category comprised mainly high school students and individuals sponsored by not-for-profit organisations. When asked why they had joined the scheme, most students stated, 'my parents registered me.' It was clear during interviews with the students that many of them did not have a good understanding of the policy and how it worked. The students tended to regard the NHIS as the responsibility of their parents so could not really be bothered about it. The other cohort of the 'sponsored NHIS holders' included those subsidised by the Daakye District Development Organisation (DDDO). The DDDO was established in 1986 to 'work in partnership with and for poor and vulnerable community members to realise their potential and make progress towards local poverty reduction'. Concerning helping individuals enrol in the NHIS, the DDDO's Executive Director argued that: 
[The] GH $\$ 4$ as administrative fee kept a lot of people from enrolling in the NHIS, so we have currently sponsored 2,350 people in different locations of the District - comprising the aged above 70, the very sick, widows and widowers and people with disabilities.

The Daakye District's NHIS manager also suggested that in 2008 the scheme sponsored almost 100 indigents. He argued that individuals that received sponsorship were vulnerable and, if not for the DDDO's assistance, they would have had no financial means to seek medical treatment in health facilities in the District.

\section{The double NHIS holders}

This subgroup encompassed teachers, health professionals, civil servants and bankers who had been transferred to work in the Daakye District. Most had joined the NHIS in their respective districts. They were aware of the paucity of health facilities in Daakyekrom; with some travelling to the big cities every weekend to access healthcare. Many joined the scheme in Daakye District because they were uncertain about what might happen to them and where they should go if injured or ill. Although money was not necessarily problematic, they were concerned that they may be involved in an accident or fall ill while in Daakye District and because of transportation difficulties be unable to leave the locality to access better health services in the home districts in which they had originally registered. As a result, they joined the NHIS locally to minimise their health financial risk while living in Daakye District.

This category of NHIS holders paid two premiums to two different district health insurance schemes. Clients of the NHIS could access healthcare in other districts provided that they transferred their registration to the district in which they were staying. However, this involved bureaucratic administrative processes that some respondents found frustrating. I asked a 30-year-old male junior secondary school teacher, who was transferred to Daakyekrom from the Greater Accra Region, why he preferred paying multiple premiums rather than transferring his registration to the Daakye District scheme. After laughing sarcastically, he said, 'It's frustratingly bureaucratic. I would not bother'.

On the same issue, Akyaa, a 28-year-old woman, remarked during an interview: 
Some succeed in transferring their registration, but it can be tiresome ... and one may have to bribe her way through. Corruption everywhere, even in health. I would rather pay the double premiums and save myself the stress of commuting to and from my home district to get my NHIS transferred, as well as the embarrassing compromise of paying bribes for what should rightfully be done for me free of charge.

It would have made logical sense for Ghanaians to register once for the NHIS and be able to use it anywhere in the country. However, the administrative process of transferring one's NHIS policy to another district was undesirably bureaucratic making the NHIS operationally inefficient.

\section{Conclusion}

This article has explored the subjective reasons for people in Daakye District to join and maintain enrolment in Ghana's NHIS. Five separate but overlapping reasons were identified. These included people who joined the policy: 1) to minimise healthcare financial risks for themselves; 2) specifically because of their dependents' (potential) health needs; and 3) to treat specific illnesses and opt out afterwards. The last two categories consisted of 4) those who had been sponsored by not-for profitorganisations; and 5) people who held 'double' NHIS policies due to difficulty transferring their policy from another district.

Ghana's NHIS was conceived as an alternative to 'out-of-pocket' payments, which had precluded especially the poor and vulnerable from accessing quality healthcare. It was expected that people would join it exclusively to minimise their personal healthcare financial risks and so it was designed with an individual focus. However, this ethnographic study has shown the dynamics behind patients' motivations and, as such, was able to identify several subgroups of NHIS clients. Although the reasons for joining the NHIS and the types of clients overlapped, the data indicated that most of the people in Daakyekrom generally related to the NHIS in terms of how it could be used to assist others (rather than themselves solely) to treat their personal health in a manner that differed from the policy's design and principal focus, which considered clients primarily on an 'individual' basis.

Theoretically, this paper confirms the findings of previous studies that people purchase health insurance policies because of what Arhinful (2003) refers to as 'self-interest' and the need to avert healthcare financing risks. However, the key point of departure is the insight presented in this text on 
the manner in which socio-cultural nuances inform people's 'self-interest'; in this regard a desire to cater for one's self and one's immediate relatives. Men were the 'breadwinners' in Daakye District. They took care of their wife(s), children, parents and sometimes other relatives. Healthcare was just one of their many responsibilities; thus, the NHIS provided them with the means to minimise the risk of incurring unexpected medical expenses. Although some of these 'breadwinners' did not access the scheme-or if they did, it was rarely used-most deemed the NHIS to be 'a must' for their dependents, even if the latter did not find it necessary. However, it should be noted that many women interviewed also intended maintaining NHIS renewal payments for their children if their husbands decided not to renew their NHIS membership. Apparently, such reasons reflected a pattern of family responsibility evident in Daakye District.

The NHIS' focus on its clients as 'individuals' has not changed since 2009; necessitating two policy recommendations. First, the findings have shown that the research participants related to the policy within a cultural context that favoured collectivism. As a result, the individual focus of the NHIS made the scheme operationally inefficient, with many clients opting in and out to exploit the policy to meet their specific personal needs. Reviewing the individual biases of the scheme to suit localities such as Daakye District — where people view themselves as part of families-is therefore critical. A recommendation would be to introduce a 'family package' option in the NHIS, allowing people to purchase a subsidised family NHIS facility to cater for a specified number of those they look after. Second, the subtly gendered undercurrents shown in the data deserve attention. The implementation of the free national maternal care system showed that women can access medical assistance themselves (without seeking men's approval) if such initiatives are backed by policy. Yet, Ghana's health policy makers will still need to embark on a strategic campaign to encourage women to purchase the NHIS directly for themselves and their dependants so they have unhindered access to medical assistance on issues that involve their personal healthcare and wellbeing.

\section{References}

Adusei-Asante, K. (2009). The National Health Insurance Scheme in practice: Motives for joining and modes of use in the Afram Plains, Ghana. Unpublished Master's Thesis. Amsterdam: Vrije University of Amsterdam.

Adusei-Asante, K., Hancock, P., \& Soares-Oliveira, M. W. (2015). Gender mainstreaming and women's roles in development projects: A 
research case study from Ghana. Advances in Gender Research, 20(12), 177-198.

Adusei-Asante, K., \& Doh, D. (2016). The two sides of free national health insurance policies: Lessons from Daakye District, Ghana. Rangsit Journal of Social Sciences and Humanities, 3(2), 37-47.

Agyepong, I. A., \& Adjei, S. (2008). Public social policy development and implementation: A case study of the Ghana National Health Insurance Scheme. Health Policy and Planning, 23, 150-160.

Arhin-Tenkorang, D. (2001). Health Insurance for informal sector in Africa: Design features, risk protection and resource mobilization. Washington, DC: CMH Working Paper Series WH3.

Arhinful, D. K. (2003). The solidarity of self-interest: Social and cultural feasibility of rural health insurance scheme in Ghana. Leiden: African Studies Centre.

Asenso-Okyere, W. K. (1995). Financing healthcare in Ghana. World Health Forum, 19, 86-91.

Asenso-Okyere, W. K., Osei-Akoto, I., Anum, A., \& Appiah, E. N. (1997). Willingness to pay for health insurance in a developing country: A pilot study of the informal sector using contingent valuation. Health Policy, 42, 233-237.

Blanchet, N. J., Fink, G., \& Osei-Akoto, I. (2012). The effect of Ghana's National Health Insurance Scheme on health care utilisation. Ghana Medical Journal, 46(2), 76-84.

Boateng, K. B. (2008). National health insurance in Ghana: Evaluation of the Nzema-east district mutual health insurance scheme. Amsterdam: Royal Tropical Institute.

Cutler, D. M., \& Zeckhauser, R. J. (2000). The anatomy of health insurance. Handbook of Health Economics, 1, 563-643.

Dixon, J., Tenkorang, E. Y., \& Luginaah, I. (2011). Ghana's National Health Insurance Scheme: Helping the poor or leaving them behind? Environment and Planning-Part C, 29(6), 1102.

Dogbevi, E. K. (2011). How Ghana improved maternal health care with international aid. https://www.ghanabusinessnews.com/2011/08/25/ how-ghana-improved-maternal-health-care-with-international-aid/.

Fenny, A. P., Asante, F. A., Arhinful, D. K., Kusi, A., Parmar, D., \& Williams, G. (2016). Who uses outpatient healthcare services under Ghana's health protection scheme and why? BMC Health Services Research, 16(1), 174. 
Ghana News Agency (2008). Government's foreign policy has paid off Kufuor. http://www.ghanaweb.com/GhanaHomePage/NewsArchive/ Government-s-foreign-policy-has-paid-off-Kufuor-152915.

Kanji, N. (1989). Charging for drugs in Africa: UNICEF's 'Bamako Initiative'. Health policy and planning, 4(2), 110-120.

Kajsa, H. A. (2008). The birth of a good health policy. http://kajsaha.com/2008/07/the-birth-of-a-good-health-policy/.

Lagomarsino, G., Garabrant, A., Adyas, A., Muga, R., \& Otoo, N. (2012). Moving towards universal health coverage: Health insurance reforms in nine developing countries in Africa and Asia. The Lancet, 380(9845), 933-943.

Ghana Ministry of Health (MOH) (2004). National Health Insurance Policy Framework for Ghana. Revised Version. Accra: $\mathrm{MOH}$.

Mariam, D. H. (2003). Indigenous social insurance as an alternative financing mechanism for health care in Ethiopia (the case of Eders). Social Science \& Medicine, 56, 1719-1726.

McPake, B., Hanson, K., \& Mills, A. (1993). Community financing of health care in Africa: an evaluation of the Bamako initiative. Social science \& medicine, 36(11), 1383-1395.

National Health Insurance Authority (2016). Capitation. http://nhis.gov.gh /capitation.aspx

Osei-Akoto, I. (2004). The economics of rural health insurance: The effects of formal and informal risk-sharing schemes in Ghana. Bonn: P.Lang

Senah, K. A. (1997). Money be man: The popularity of medicines in a rural Ghanaian community. Amsterdam: Universiteit van Amsterdam.

Yeboah, K. P. (2008). Harmonization challenges of recent health reforms for the Christian health association of Ghana (CHAG). Amsterdam: Royal Tropical Institute. 